\section{Henoch-Schonlein purpura: ultrasonography of scrotal and penile involvement}

\author{
Youngsik Lim', Boem Ha Yi', Hae Kyung Lee', Hyun Sook Hong ${ }^{1}$, Min Hee Lee', \\ Seo-Youn Choi ${ }^{1}$, Jae Ock Park ${ }^{2}$ \\ Departments of ${ }^{1}$ Radiology and ${ }^{2}$ Pediatrics, Soonchunhyang University Bucheon Hospital,
} Bucheon, Korea

Testicular or scrotal involvement has been reported in children with Henoch-Schonlein purpura (HSP), but there are very few reports on penile involvement. We report the initial and followup ultrasonographic findings of scrotal and penile involvement of HSP in a 5-year-old boy. On ultrasonography, scrotal soft tissue thickening and epididymal swelling with increased vascularity were noted, and on the penis, a focal mass-like lesion appeared on the dorsal surface of the distal penis, having a hypoechoic mass-like appearance without visible vascular flow on a Doppler study. After 2 days of treatment, follow-up ultrasonography showed normal scrotum and penis with a resolved soft tissue mass-like lesion. Therefore, we think that HSP ultrasonographic findings involving the scrotum and penis might help to diagnose scrotal and penile involvement in a case of HSP and to avoid unnecessary medication and/or surgical procedures.

Keywords: Purpura, Schonlein-Henoch; Ultrasonography; Penis; Scrotum

\section{Introduction}

Henoch-Schonlein purpura (HSP) is a systemic non-thrombocytopenic IgA-mediated vasculitic disease. HSP is the most common vasculitis in children and mainly affects the small vessels of the skin, joints, gastrointestinal (GI) tract, and kidneys [1]. Boys are affected more often than girls [1]. The mean age of HSP patients is 6 years; $75 \%$ of patients are $<8$ years of age and $90 \%$ are $<10$ years of age [2]. HSP is characterized by a classic tetrad of non-thrombocytopenic palpable purpura, arthritis or arthralgia, and $\mathrm{GI}$ tract and renal involvement [3]. Cutaneous involvement is the most common presentation [3]. Although HSP is a clinical diagnosis, tissue biopsy may be helpful when the presentation is atypical [3]. A wide variety of manifestations involving the genitourinary tract have been reported in children with HSP. Among these non-renal genitourinary manifestations, testicular or scrotal involvement has been reported, but penile involvement is very rare [4-6]. Here, we report the initial and follow-up ultrasonographic findings of the scrotal and penile involvement of HSP in a 5 -year-old boy.

\section{Case Report}

A previously healthy 5-year-old boy was admitted to our hospital with a short history of a rash and

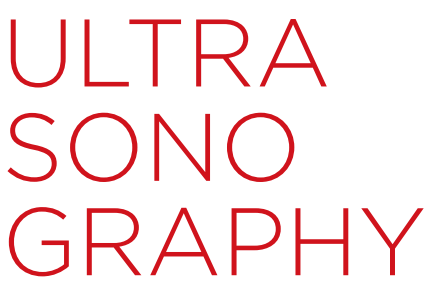

\section{CASE REPORT}

http://dx.doi.org/10.14366/usg.14042 pISSN: 2288-5919 e elSSN: 2288-5943

Ultrasonography 2015;34:144-147

Received: September 18, 2014

Revised: November 26, 2014

Accepted: November 26, 2014

Correspondence to:

Boem Ha Yi, MD, PhD, Department of Radiology, Soonchunhyang University Bucheon Hospital, 170 Jomaru-ro, Wonmi-gu, Bucheon 420-767, Korea

Tel. +82-32-621-5851

Fax. +82-32-621-5874

E-mail: rad1995@schmc.ac.kr

This is an Open Access article distributed under the terms of the Creative Commons Attribution NonCommercial License (http://creativecommons.org/ licenses/by-nc/3.0/) which permits unrestricted noncommercial use, distribution, and reproduction in any medium, provided the original work is properly cited.

Copyright @ 2015 Korean Society of Ultrasound in Medicine (KSUM)

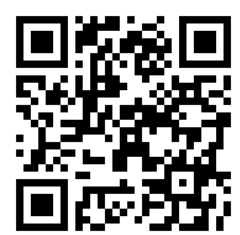

How to cite this article:

Lim Y, Yi BH, Lee HK, Hong HS, Lee MH Choi SY, et al. Henoch-Schonlein purpura: ultrasonography of scrotal and penile involvement. Ultrasonography. 2015 Apr; 34(2):144-147 
abdominal pain. His medical history was unremarkable, and no drug intake was reported. His parents reported a palpable non-blanching purpuric rash over his lower extremities that had been present for 2 days. The rash extended to the upper extremities, and the patient complained of abdominal pain on the day before admission. Laboratory data obtained on admission showed a hemoglobin level of $12.5 \mathrm{~g} / \mathrm{dL}$, a white blood cell count of $11,020 / \mathrm{mm}^{3}$ with a normal differential count, and slightly elevated IgA (211 mg/dL). Other laboratory data were within normal limits. A urinalysis showed no proteinuria or hematuria. The patient was treated with intravenous fluids as conservative treatment under the impression of HSP. After

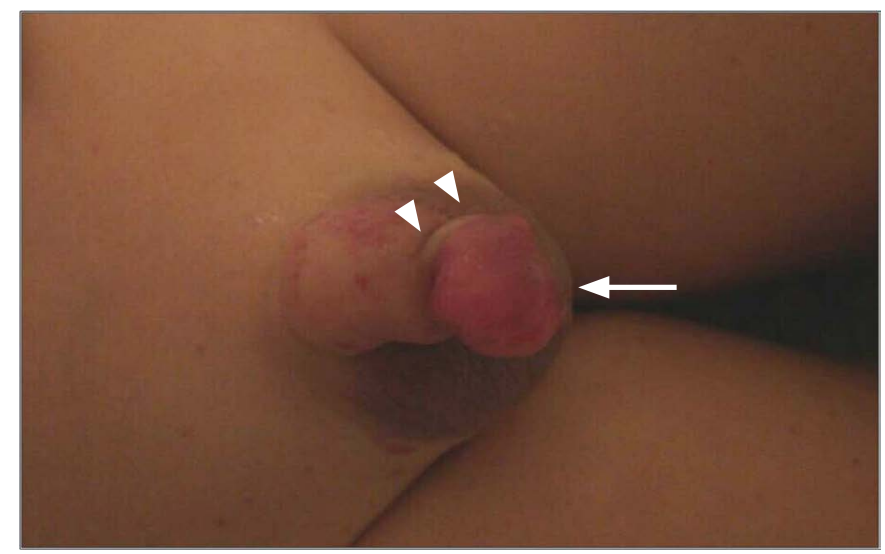

A

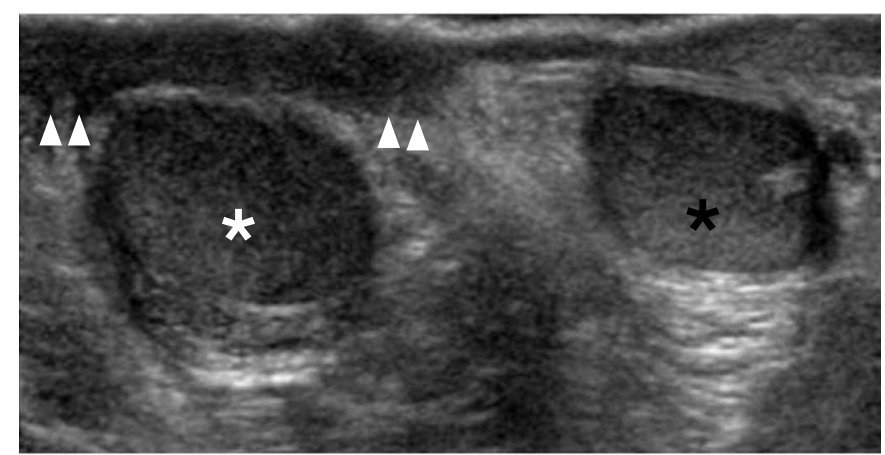

B

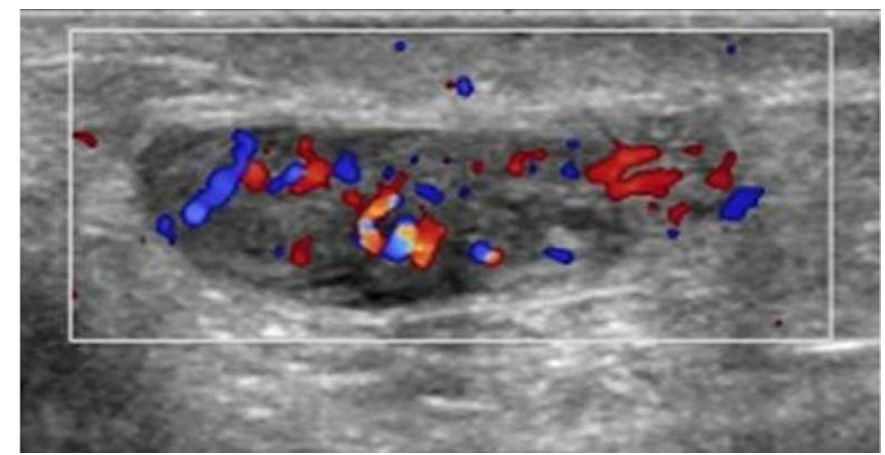

D admission, he complained of pain in the right knee and elbow joint with swelling and was started on $1 \mathrm{mg} / \mathrm{kg} /$ day of oral prednisolone.

The joint and abdominal pain improved by hospital day 17 . However, both sides of the scrotum became edematous and tender with a purpuric rash. The penis also showed swelling and a purpuric rash with a focal reddish mass-like lesion at the penile tip. The reddish mass-like lesion caused skin twisting at the base with mild deviation of the penile axis (Fig. 1A). The patient did not complain of pain in the penile shaft or in the reddish mass-like lesion at the penile tip. No history of trauma was reported, and no evidence of a urinary tract infection or hematuria was detected. The phallus was

Fig. 1. A 5-year-old boy with symptoms of Henoch-Schonlein purpura.

A. Photograph shows the swelling of the right scrotum and the penis with a purpuric rash and a reddish mass-like lesion (arrow) at the penile tip. The reddish mass-like lesion causes skin twisting at the base (arrowheads) with mild deviation of the penile axis. B. Transverse ultrasonogram shows bilateral scrotal soft tissue thickening; more severe on the right side (arrowheads). White and black asterisks indicate the right and left testicles, respectively. C-E. Longitudinal grayscale (C) and color Doppler (D, E) ultrasonograms of the right epididymis show swelling with increased vascularity at the head and body (C, D). The tail of the right epididymis (arrow) also shows swelling with increased vascularity (E). The white asterisk indicates the right testicle.

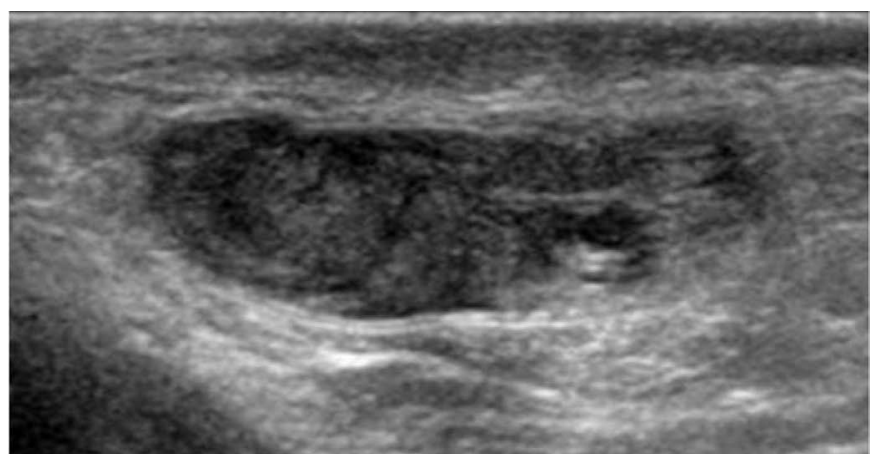

C

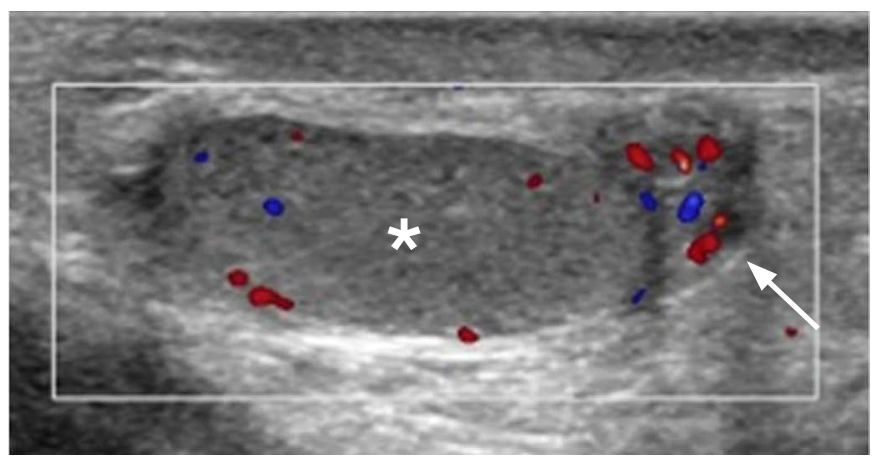

E 


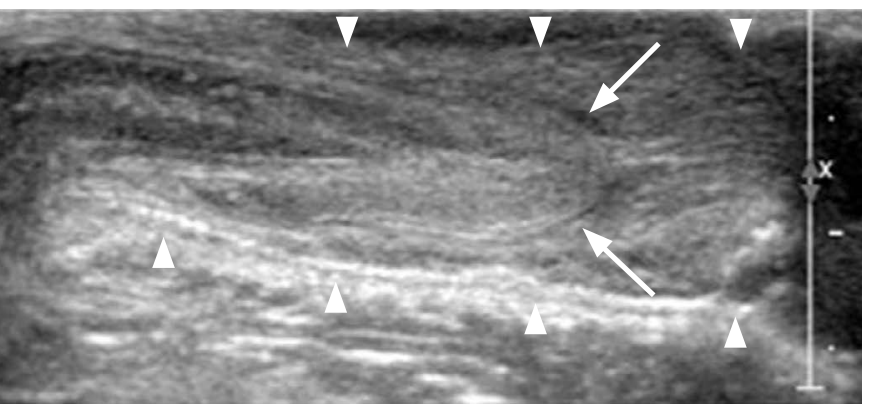

F

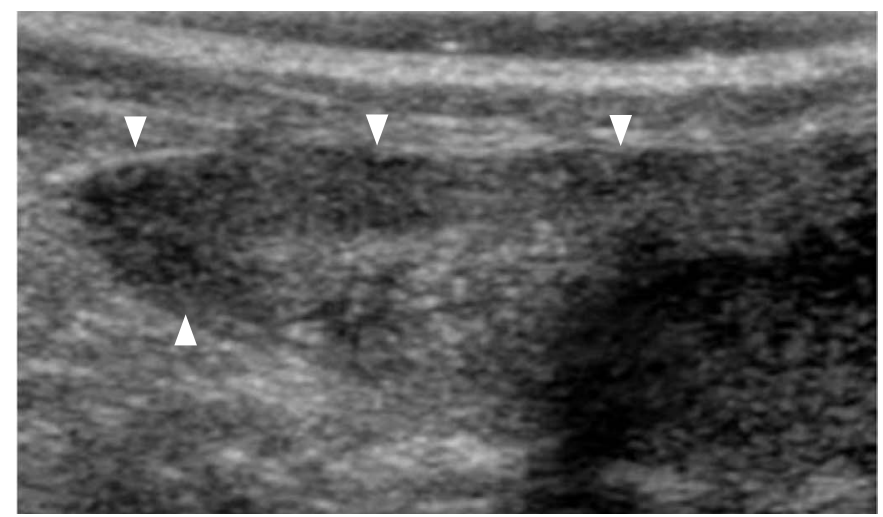

$\mathrm{H}$

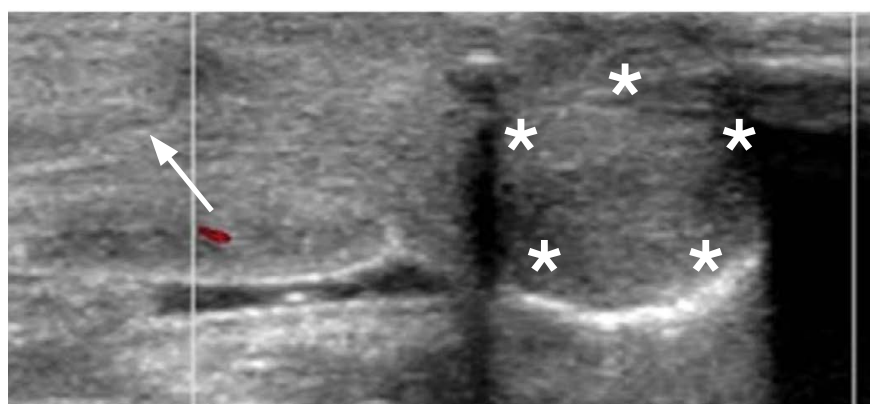

G

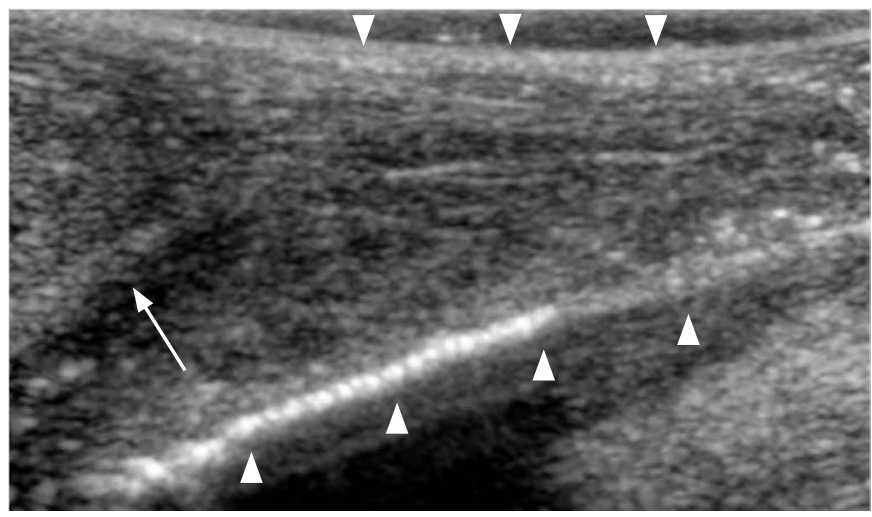

।

Fig. 1. F, G. Longitudinal grayscale (F) and color Doppler (G) ultrasonograms of the penis show the swelling of the penile shaft and foreskin (arrowheads), and a well-defined hypoechoic mass-like lesion measuring about $1.4 \mathrm{~cm} \times 1.3 \mathrm{~cm}$ (asterisks) without vascularity on the penile tip. Arrows indicate the glans penis. H. Follow-up longitudinal ultrasonogram of the right epididymis (arrowheads) shows no swelling. I. Follow-up longitudinal ultrasonogram of the penis shows no swelling of the penile shaft and foreskin (arrowheads). The hypoechoic masslike lesion at the penile tip has disappeared. The arrow indicates the glans penis.

uncircumcised, and the patient voided without difficulty or pain and had a normal urinary stream. The patient was referred for emergency scrotal ultrasound examination. On ultrasonography, bilateral scrotal soft tissue thickening was noted. It was more severe on the right side (Fig. 1B), and the right epididymis was swollen with increased vascularity, mimicking bacterial epididymitis (Figs. 1C-E). The size, echogenicity, and vascularity of both testicles were within normal limits. The penile shaft and foreskin were also swollen (Fig. 1F), and there was a well-defined hypoechoic mass-like lesion (dimensions, $\sim 1.4 \mathrm{~cm} \times 1.3 \mathrm{~cm}$ ) without vascularity on the penile tip (Fig. 1G). This lesion was not connected with the corpus cavernosum, corpus spongiosum, or glans, and seemed to originate from the tip of the foreskin. Although the lesion did not show vascularity in a Doppler study, the patient did not complain of any pain in the penile area or voiding difficulty. Follow-up ultrasonography was recommended under the impression of HSP-related large ecchymosis or purpura with a blister on the penile tip. The edema, purpuric rash, and pain in the scrotum completely subsided as did the reddish mass-like lesion on the penile tip after 2 days of continuous treatment with oral prednisolone. The penile axis also became normal. Followup ultrasonography showed no scrotal or penile edema and no epididymal swelling (Fig. 1H), and the hypoechoic mass-like lesion on the penile tip had disappeared (Fig. 11).

\section{Discussion}

Scrotal and penile swellings were the dominant features of the illness of our patient, together with rashes on the upper and lower extremities, abdominal pain, and disabling arthralgia in the knee and elbow joints. While the diagnosis of HSP in this particular case was not complicated, the bilateral scrotal and penile involvement, particularly the reddish mass-like lesion on the penile tip, was an unusual manifestation.

Extrarenal genitourinary manifestations of HSP include acute scrotum, ureteritis with associated hydronephrosis, hematoma of the bladder wall, urethritis, hemorrhagic spermatic cord, priapism, thrombosis of the spermatic veins, and epididymo-orchitis [5]. The first case of male genital involvement of HSP was reported by Allen 
et al. in 1960 [7]. Since then, there have been reports of scrotal involvement in cases of HSP varying from $2 \%$ to $38 \%$, and HSP with scrotal involvement makes up approximately $3 \%$ of all cases of acute scrotum [8]. The presentation may include scrotal rash, swelling, and either bilateral or unilateral pain. Penile involvement of HSP in children has been reported, but such cases are very rare [4-6]. Ziaee and Moradinejad [9] reported the cases of 20-56 male patients that had genital involvement (75\% scrotal swelling, 45\% epididymo-orchitis-like symptoms, 5\% penis inflammation, and $5 \%$ meatus inflammation).

Acute scrotal swelling may be an emergency condition, and the differential diagnosis includes testicular torsion requiring immediate surgical treatment. HSP is a type of systemic vasculitis, and the scrotum can be a part of systemic vasculitis. Scrotal involvement in HSP should be managed conservatively, not surgically. The clinical presentation of HSP with acute scrotum may mimic testicular torsion. Several reports have described patients with HSP who also had signs of testicular torsion and were explored surgically. In almost all cases, the patients had no torsion but had vasculitic changes in the spermatic cord and testes $[8,10]$. Sonographic findings of patients with acute scrotal pain and HSP are epididymal enlargement, scrotal skin thickening, hydrocele, and normal-appearing testes with normal intratesticular blood flow [11]. These sonographic findings correlate with the reported histology: an aseptic, necrotic vasculitis and hemorrhage (acute leukocytoclastic inflammatory reaction), involving primarily the epididymis [11]. Normal-appearing testes on sonography can make torsion an unlikely diagnosis. The sonographic findings of scrotal involvement of HSP can allow distinction from torsion in most cases and have high sensitivity $(89 \%-100 \%)$ and specificity $(97 \%-100 \%)$ [12].

To the best of our knowledge, no reports on sonographic findings of penile involvement in the case of HSP have been published thus far, and in our case, the penile ultrasound revealed diffuse swelling of the penile shaft and foreskin with a well-defined hypoechoic mass-like lesion on the penile tip. The well-defined hypoechoic mass-like lesion without vascularity on the penile tip, which caused skin twisting at the base with mild deviation of the penile axis, was an unusual finding that had not been reported earlier.

Our patient seemed to respond to steroids, but steroid therapy is controversial in the cases of scrotal and penile involvement. Although some reports have stated that symptoms resolve after prednisolone treatment, other reports have indicated that symptoms resolved spontaneously without any treatment in some cases $[4,5]$.

In conclusion, this report discusses an uncommon presentation of HSP with bilateral scrotal and penile involvement. We believe that HSP ultrasonographic findings involving the scrotum and the penis might help to diagnose a case of HSP with scrotal and penile involvement and to avoid unnecessary medication and/or surgical procedures.

ORCID: Youngsik Lim: http://orcid.org/0000-0002-6011-2755; Boem Ha Yi: http://orcid.org/0000-0003-2917-260X; Hae Kyung Lee: http://orcid.org/0000-00030037-3416; Hyun Sook Hong: http://orcid.org/0000-0003-3210-9740; Min Hee Lee: http://orcid.org/0000-0001-9198-0814; Seo-Youn Choi: http://orcid.org/0000-00022434-8779; Jae Ock Park: http://orcid.org/0000-0003-2334-0350

\section{Conflict of Interest}

No potential conflict of interest relevant to this article was reported.

\section{References}

1. Saulsbury FT. Clinical update: Henoch-Schonlein purpura. Lancet 2007;369:976-978.

2. Calvino MC, Llorca J, Garcia-Porrua C, Fernandez-Iglesias JL, Rodriguez-Ledo P, Gonzalez-Gay MA. Henoch-Schonlein purpura in children from northwestern Spain: a 20-year epidemiologic and clinical study. Medicine (Baltimore) 2001;80:279-290.

3. Kamath $\mathrm{N}$, Rao $\mathrm{S}$. Henoch-Schonlein purpura: an update. Indian $J$ Rheumatol 2012;7(Suppl 1):92-98.

4. David S, Schiff JD, Poppas DP. Henoch-Schonlein purpura involving the glans penis. Urology 2003;61:1035.

5. Ferrara P, Marrone G, Nicoletti A, Mastrangelo A, Tiberi E, Rigante D, et al. Penile involvement in Henoch-Schonlein purpura with good prognosis. Scand J Urol Nephrol 2007;41:567-569.

6. Caliskan B, Guven A, Atabek C, Gok F, Demirbag S, Surer I. Henoch-Schonlein purpura presenting with symptoms mimicking balanoposthitis. Pediatr Rep 2009;1:e5.

7. Allen DM, Diamond LK, Howell DA. Anaphylactoid purpura in children (Schonlein-Henoch syndrome): review with a follow-up of the renal complications. AMA J Dis Child 1960;99:833-854.

8. Clark WR, Kramer SA. Henoch-Schonlein purpura and the acute scrotum. J Pediatr Surg 1986;21:991-992.

9. Ziaee V, Moradinejad MH. Unusual organ involvement in HenochSchonlein purpura patients: a roprt from Iran. Pediatr Rheumatol 2011;9(Suppl 1):99.

10. O'Regan S, Robitaille P. Orchitis mimicking testicular torsion in Henoch-Schonlein's purpura. J Urol 1981;126:834-835.

11. Ben-Sira L, Laor T. Severe scrotal pain in boys with HenochSchonlein purpura: incidence and sonography. Pediatr Radiol 2000:30:125-128.

12. Huang LH, Yeung CY, Shyur SD, Lee HC, Huang FY, Wang NL. Diagnosis of Henoch-Schonlein purpura by sonography and radionuclear scanning in a child presenting with bilateral acute scrotum. J Microbiol Immunol Infect 2004;37:192-195. 